\title{
TESTING SUSTAINABILITY BY PROSPECTIVE AND RETROSPECTIVE DEMOGRAPHIC ANALYSES: EVALUATION FOR PALM LEAF HARVEST
}

\author{
Pieter A. Zuidema, ${ }^{1,2,4}$ Hans de Kroon, ${ }^{3}$ and Marinus J. A. Werger ${ }^{1}$ \\ ${ }^{1}$ Section of Plant Ecology and Biodiversity, Faculty of Science, Utrecht University, P.O. Box 80084, 3508 TB Utrecht, The Netherlands \\ ${ }^{2}$ Programa Manejo de Bosques de la Amazonía Boliviana (PROMAB), Casilla 107, Riberalta, Bolivia \\ ${ }^{3}$ Department of Ecology, Radboud University, Toernooiveld 1, 6525 ED Nijmegen, The Netherlands
}

Abstract. Harvesting nontimber forest products (NTFPs) is a major economic activity in tropical forests. As many NTFPs are overexploited, sustainability analyses are required to set harvest guidelines. Here we introduce and apply a new approach to evaluating sustainability, which combines prospective (elasticity) and retrospective (Life Table Response Experiments [LTRE]) demographic analyses of matrix population models. We relate the elasticity of vital rates (representing their importance for population growth rate, $\lambda$ ) to their contribution to harvest-induced change in $\lambda$ ("LTRE contribution"). When high-elasticity vital rates have a low LTRE contribution, exploitation is potentially sustainable as negative effects for population growth are buffered. If the reverse is found, there is little scope for sustainability because crucial vital rates are affected. Our approach is less sensitive to chance fluctuations than the commonly used sustainability criterion of $\lambda=1.0$, as it does not depend on the absolute value of $\lambda$.

We applied this analysis to Geonoma deversa, a clustered forest understory palm. We studied three experimentally defoliated and control populations in a Bolivian rainforest during two years. Cutting all leaves of large ramets did not change mortality but strongly affected growth and reproduction. In spite of severe changes in some vital rates, population growth rate was not significantly reduced after defoliation. A literature review revealed that six other understory palms species responded very similarly to defoliation.

The combination of LTRE contributions and elasticity analyses showed that low-elasticity vital rates were mainly responsible for the defoliation-induced change in $\lambda$ for Geonoma deversa. For two other understory palms (Astrocaryum mexicanum and Chamaedorea radicalis) new demographic analyses yielded very similar results. For Geonoma, the LTRE contribution-elasticity relation strongly changed when we mimicked harvest damage. Adding $5 \%$ mortality to defoliated palms caused stronger change in $\lambda$, mainly due to changes in a highelasticity vital rate (survival). Therefore, harvest practices that involve stem killing are clearly unsustainable.

Our results show that commercial leaf cutting in Geonoma deversa is potentially sustainable, and that this is likely the case for understory palms in general. Our approach to evaluating harvest sustainability can be applied to other NTFPs.

Key words: Bolivia; defoliation; demography; elasticity analysis; Geonoma deversa; Life Table Response Experiments (LTRE); nontimber forest products (NTFP); population matrix models; sustainability, tropical forest.

\section{INTRODUCTION}

A vast amount of nontimber forest products (NTFPs) are obtained from natural forests worldwide (FAO 2005). The harvest of these products has been presented as an environmentally responsible and sustainable way to exploit forests, compared to logging trees for timber. In spite of the limited impact of NTFP harvest on forest structure (Ticktin 2004), overexploitation of NTFPs is often reported (e.g., Flores and Ashton 2000, Guillen et al. 2002). To sustain economic gains from these products and certify their exploitation it is necessary to evaluate

Manuscript received 23 December 2005; revised 31 March 2006; accepted 13 April 2006; final version received 9 May 2006. Corresponding Editor: E. Cuevas.

${ }^{4}$ E-mail: p.a.zuidema@bio.uu.nl harvest impact and design harvest guidelines (Hall and Bawa 1993, Guillen et al. 2002, Peres et al. 2003).

Demographic studies play an important role in sustainability analysis of NTFP harvest (Boot and Gullison 1995) and have been conducted for a number of exploited species (Ticktin 2004). In such studies a commonly used criterion for sustainability is the population growth rate $(\lambda)$ obtained from matrix models (Caswell 2001): a value of $<1.0$ indicates population decline and is often interpreted as unsustainable (e.g., Bernal 1998, Svenning and Macia 2002). Although conceptually sound, applying the value of $\lambda$ has practical drawbacks as it is strongly affected by variation in vital rates (growth, survival, and reproduction) and uncertainty in their estimation (e.g., Wisdom et al. 2000, Zuidema and Franco 2001). Here we present and apply 
an approach to evaluate sustainability of NTFP extraction that is less sensitive to chance fluctuations. To this end we introduce two analyses.

First, we relate the harvest effect on vital rates with their importance for $\lambda$, as measured by elasticity (de Kroon et al. 2000). If all vital rates were equally affected by harvest, there would be no difference in harvest effect between low- and high-elasticity vital rates. Alternatively, if vital rates are differentially affected by harvest, the relation between elasticity and harvest effect may serve as a first evaluation of sustainability. In the case that high-elasticity vital rates are much less affected by harvest than low-elasticity vital rates, there may be scope for sustainable harvest.

Although the finding that high-elasticity vital rates suffer little harvest impact may be indicative for sustainability, small decreases in these vital rates may considerably reduce $\lambda$ and cause population decline. Therefore, it is necessary to take into account the impact of vital rate changes for the harvest-induced change in $\lambda$. To this end, our second analysis includes life table response experiments (LTRE; Caswell 2001) to detect the contributions of vital rate changes to $\Delta \lambda$. LTRE analysis is a retrospective technique (sensu Horvitz et al. 1997), as it looks back at the consequences of variation in vital rates for observed variation in $\lambda$. In contrast, elasticity analysis is a prospective technique, as it looks forward by answering the question: "What would happen if a certain vital rate would be changed?" By combining results of LTRE and elasticity analysis it is possible to evaluate whether the contributions to $\Delta \lambda$ (hereafter "LTRE contributions") are mainly due to important (high-elasticity) vital rates or to unimportant (low-elasticity) vital rates. For a null model in which all vital rates are equally affected by harvest, high-elasticity vital rates are expected to have the highest LTRE contributions as both parameters depend on sensitivity (Caswell 2001): high-sensitivity vital rates have both a high elasticity and lead to large LTRE contributions when they are changed. Alternatively, if vital rates differ in harvest response, the relation between elasticity and LTRE contribution can be used to evaluate sustainability. In the case that high-elasticity vital rates have a low LTRE contribution, and vice versa, harvest is likely to be sustainable. In that case, the differential harvest response of vital rates buffers the negative effects for $\lambda$.

Here we apply the above approach to evaluate the effects of complete defoliation on the Neotropical forest understory palm Geonoma deversa and assess its potential for sustainable leaf harvest. Leaves of this species are harvested and traded for roof thatching in Bolivia, Peru, and Brazil (Moraes et al. 1995, Flores and Ashton 2000). Many other species of understory palms are also exploited for leaves, which are then used for basketry, thatching, or in the floral industry. Defoliation studies showed that understory palms are remarkably tolerant to complete defoliation (e.g., Mendoza et al. 1987, Oyama and Mendoza 1990, Chazdon 1991). To evaluate whether this tolerance at the individual level also implies potential for sustainable use at the population level, we present new LTRE analyses for two palm species for which demography has been published, and we review published data on defoliation responses and elasticity patterns for a wider group of understory palms. Our aims were: (1) to evaluate whether complete defoliation in Geonoma deversa is potentially sustainable, (2) to assess whether other understory palm species show similar population-level responses to defoliation, and (3) to demonstrate how prospective and retrospective matrix analyses can be combined to analyze sustainable NTFP harvesting.

\section{Methods \\ Study species}

Geonoma deversa (Poit.) Kunth is a Neotropical understory palm that often occurs in high-density stands (Wessels Boer 1968). The species has a clustered growth form (i.e., ramets, or shoots, within a genet, or clone, remain connected). Ramets are formed by basal sprouting and the rooting system is shared among ramets; individual ramets cannot survive when disconnected from the genet. Genets consist of up to 11 ramets and are long lived (up to 300 years; Zuidema 2000). Ramets are $<4 \mathrm{~m}$ high and short lived $(<50 \mathrm{yr})$. Leaves are harvested from ramets of $\geq 120 \mathrm{~cm}$ stem length, which occurred at a density of $38 \pm 8$ ramets $/ 100 \mathrm{~m}^{2}$ in our study plots.

Two types of leaf cutting are applied: cutting only the leaves without damaging the ramet, and cutting the upper part of the ramet, causing its death (Flores and Ashton 2000, Svenning and Macia 2002). For longlasting and high-quality thatches with a commercial value the first method is applied, which we mimicked in our experiment. Usually, harvest intensity is $100 \%$ (all leaves of all large ramets in a stand are harvested) and harvesters tend to come back after a variable number of years to harvest the stand again. Roughly 1000 leaves are needed for $1 \mathrm{~m}^{2}$ of roof thatch.

\section{Data collection and analysis}

The study was carried out in the Northern Bolivian Amazon, close to the forest community of El Turi (Pando Department, $11^{\circ} 45^{\prime} \mathrm{S}, 67^{\circ} 20^{\prime} \mathrm{W}$ ). The area is covered by lowland moist forest with a mean annual precipitation of $1700-1800 \mathrm{~mm}$ and a dry spell from May to September during which monthly precipitation does not exceed $100 \mathrm{~mm}$. During the second measurement year, rainfall during the wet and dry seasons was considerably reduced $(985 \mathrm{~mm}$ and $94 \mathrm{~mm}$ in wet and dry season, respectively, compared to long-term means of 1037 and $203 \mathrm{~mm}$ ).

Three high-density, representative stands of Geonoma deversa in undisturbed primary forest areas with no signs of recent leaf cutting were selected. In each stand a control plot $(30 \times 30 \mathrm{~m})$ and a defoliation plot $(20 \times 30$ $\mathrm{m})$ were installed, and all were divided into $10 \times 10 \mathrm{~m}$ 
subplots. In November 1996 genets and ramets $(>20 \mathrm{~cm}$ height to tip of newest leaf) were searched, measured, and tagged in the entire control plots or in as many subplots within the control plots as necessary to obtain sufficient individuals. In February 1997 seedlings (with at least one unfolded leaf) were searched, counted, and measured in $9 \mathrm{~m}^{2}$ areas in the corner of each subplot in the control plot. In the three control plots 192 stemless individuals (including seedlings) and 864 stemmed ramets were studied, belonging to a total of 357 genets.

In each of the three defoliation plots all genets with at least one large ramet $(>120 \mathrm{~cm}$ stem length) were identified and from this pool four or five genets per size category $(1-3,4-6,7-9$, and $>9$ large ramets) were randomly selected for defoliation. Selected genets were tagged, measured, and defoliated in November 1996. The defoliation treatment consisted of cutting all green leaves of ramets of $>120 \mathrm{~cm}$ stem length without damaging the ramet. Leaves were cut from a total of 234 ramets belonging to 51 genets. Defoliated genets lost $77 \%$ of their leaves, on average.

Measurements of defoliated and control populations were carried out at the study onset and after one and two years. On stemless individuals, we measured the length of the youngest fully expanded leaf and the number of bifid (juvenile) and dissected (adult) leaves. On each stemmed ramet, we measured total stem length, number of green leaves, whether the ramet had been or was reproductive at the time of measurement (i.e., with flowers or fruits), and whether it had produced new ramets vegetatively. Leaf production rate, stem growth rate, and length of new internodes were calculated for both measurement years. On multistemmed genets, we also recorded the number of recently emerged ramets $(<10 \mathrm{~cm}$ stem length). Other genet parameters were derived by summing over all ramets the total stem length and the total number of leaves. Leaf length was measured for all ramets ( $>10 \mathrm{~cm}$ stem length) of 18 randomly selected genets in the control plots and 20 genets in the defoliation plots. Recruitment of new seedlings was determined annually in the seedling subplots within the control plots.

Defoliation effects on vital rates were tested using multiple regression models that accounted for size effects (for growth, survival, and leaf production rates) and chi-square tests (for reproduction). In all tests, data from the control plot were used as a control to test for defoliation effects.

\section{Matrix model construction and parameterization}

The effects of leaf cutting for population dynamics were assessed using matrix models (Caswell 2001). Matrix models are of the form: $\mathbf{n}(t+1)=\mathbf{A} \times \mathbf{n}(t)$, where $\mathbf{n}(t)$ and $\mathbf{n}(t+1)$ are population structures at time $t$ and $t+1$, respectively, and $\mathbf{A}$ is a transition matrix containing probabilities of transitions among categories. Transition matrices used here combined genet and ramet demography by categorizing ramets based on their own size and that of the genet to which they belonged (see Appendix, Fig. A1). Nine genet categories were distinguished based on leaf number, leaf type, and stem length summed over all ramets (of $>10 \mathrm{~cm}$ stem length): (1) seedlings with 1-3 juvenile leaves; (2) seedlings with 4-6 juvenile leaves; (3) single-stemmed genets with 1-3 adulttype leaves and $<10 \mathrm{~cm}$ stem length; (4) single- or multistemmed genets of 10-250 cm summed stem length; (5) idem for 250-500; (6) idem for 500-1000 cm; (7) idem for 1000-1500 cm; (8) idem for 1500-2000 cm; and (9) idem for $>2000 \mathrm{~cm}$. Three ramet categories were distinguished based on stem length: (a) ramets of 10$120 \mathrm{~cm}$; (b) $120-230 \mathrm{~cm}$; and (c) $>230 \mathrm{~cm}$. Ramets in the latter category hardly ever occurred in genets of categories 4 and 5, and were therefore omitted in these genet categories.

Four transition matrices were constructed: $\mathbf{U} \mathbf{1}$ and $\mathbf{U} \mathbf{2}$ for the undisturbed population in the first and second measurement year, respectively; and $\mathbf{C 1}$ and $\mathbf{C 2}$ for the defoliated populations during the first and second measurement year (coinciding with the first and second year after defoliation). Data from the three study stands were merged as these did not differ or hardly differed in vital rates.

Transitions were calculated based on values of vital rates (survival, growth, flowering, seedling recruitment, vegetative reproduction) as this allowed us to directly translate the defoliation effects to the transition matrices (see Appendix). Transition values in matrices $\mathbf{C 1}$ and $\mathbf{C 2}$ were based on matrices $\mathbf{U} \mathbf{1}$ and $\mathbf{U} \mathbf{2}$, respectively, and only differed for those vital rates that were significantly affected by defoliation (see Appendix).

\section{Analyzing leaf cutting effects at the population level}

To validate matrix model output, we compared the stable stage distribution obtained from C1 (right eigenvector, ssd) with the observed population structure (mean of three stands, obs), using the percentage similarity index (PS; Horvitz and Schemske 1995): PS $=\Sigma\left(\min \left[\operatorname{obs}_{i}, \operatorname{ssd}_{i}\right]\right) \times 100$, where obs and ssd are scaled to one. High values of this index indicate a high level of similarity.

To evaluate the population consequences of defoliation, we conducted several matrix analyses. First, we calculated the asymptotic growth rates $\lambda$ of undisturbed (U1, U2) and defoliated populations (C1, C2). We calculated confidence intervals of $\lambda$ using the series approximation approach (Caswell 2001) and observed levels of variance for vital rates. Second, we calculated elasticities for vital rates (Caswell 2001:232), not for matrix elements, for all four matrices. Elasticity values indicate the proportional change in population growth rate due to a proportional change in vital rate (de Kroon et al. 2000). Third, we analyzed the contributions of vital rates to the observed changes in population growth rate $(\Delta \lambda)$, using fixed-effect Life Table Response Experiments (LTRE) on lower level parameters (Caswell 2001:261, Cooch et al. 2001) for the first and second 
TABLE 1. Effects of complete defoliation on growth and survival of Geonoma deversa ramets.

\begin{tabular}{|c|c|c|c|c|c|c|c|c|c|}
\hline \multirow[b]{2}{*}{ Parameter } & \multirow[b]{2}{*}{ Year } & \multirow[b]{2}{*}{$R^{2}$} & \multirow[b]{2}{*}{$C$} & \multirow[b]{2}{*}{ Defoliation } & \multirow{2}{*}{$\begin{array}{c}\text { Change } \\
(\%)\end{array}$} & \multirow{2}{*}{$\begin{array}{l}\text { Stem length } \\
(\mathrm{cm})\end{array}$} & \multicolumn{2}{|c|}{ Leaf number } & \multirow[b]{2}{*}{$n$} \\
\hline & & & & & & & Genet & Ramet & \\
\hline Ramet survival $\left(\sigma_{k}\right)$ & $1-2$ & 0.14 & 1.32 & & & $-0.01 * *$ & & $0.49^{* * *}$ & 1072 \\
\hline \multirow[t]{2}{*}{ Stem growth, a $\left(\gamma_{k}\right) \dagger$} & 1 & 0.30 & 0.38 & & & $-0.08 * * *$ & $0.07 * * *$ & $2.03 * * *$ & 281 \\
\hline & 2 & 0.43 & -0.50 & & & $-0.12 * * *$ & $0.07 * * *$ & $2.29 * * *$ & 245 \\
\hline \multirow[t]{2}{*}{ Stem growth, b-c $\left(\gamma_{k}\right) \dagger$} & 1 & 0.35 & 1.54 & $-2.98 * * *$ & -43 & $-0.01 * * *$ & $0.01 *$ & $0.86^{* * *}$ & 768 \\
\hline & 2 & 0.39 & 0.38 & $3.41 * * *$ & -29 & $-0.02 * * *$ & & $0.97 * * *$ & 781 \\
\hline
\end{tabular}

Notes: Results of multiple forward regression models for stem growth (linear) and survival (logistic): coefficient of determination (Nagelkerke $R^{2}$ for logistic), constant $(C)$, regression coefficient, and significance level $\left({ }^{*} P<0.05 ; * * P<0.01 ; * * * P<0.001\right)$; and percentage change in stem growth due to defoliation (Change).

$\dagger$ Ramets in category a are $10-120 \mathrm{~cm}$ stem length; ramets in categories $\mathrm{b}$ and $\mathrm{c}$ are $>120 \mathrm{~cm}$ stem length.

year after defoliation (C1 vs. U1 and C2 vs. U2). We used vital rate sensitivities of matrices "midway" between the compared matrices (Caswell 2001). Next, we correlated the relative change (mainly decrease) of vital rates due to defoliation with their elasticity value for undisturbed populations. Finally, we related elasticity values to the contribution of vital rates to $\Delta \lambda$ obtained from LTRE analysis. We also performed this analysis after changing the survival rate of defoliated individuals, to mimic additional harvest damage. All matrix analyses were carried out in MATLAB (MathWorks, Natick, Massachusetts, USA).

\section{Defoliation responses in other understory palms}

We examined the generality of defoliation responses of understory palms by synthesizing published results of defoliation experiments and population dynamics of other species, using literature searches and reviews (Franco and Silvertown 2004, Ticktin 2004). For two species, Chamaedorea radicalis (Endress et al. 2004a, b) and Astrocaryum mexicanum (Piñero et al. 1984, Mendoza et al. 1987), we used published modeling results to carry out new LTRE analyses.

\section{RESULTS}

\section{Consequences of leaf cutting at the individual level}

The effect of complete defoliation in Geonoma deversa differed considerably among vital rates. Vegetative reproduction dropped by $70 \%$ in the first year after defoliation: only $4 \%$ of defoliated genets reproduced vegetatively, compared to $13 \%$ of the undisturbed genets $\left(\chi^{2}=3.48, P=0.06, n=255\right)$. In the dry second year this was $0 \%$ and $4 \%$, respectively $\left(\chi^{2}=2.28, P>0.05, n=\right.$ 186). Also sexual reproduction strongly decreased: in the first year $39 \%$ of the undisturbed large ramets reproduced compared to $23 \%$ of the defoliated ramets $\left(\chi^{2}=\right.$ 16.5, $P<0.001, n=778)$; in the second year these percentages were $64 \%$ and $26 \%$, respectively $\left(\chi^{2}=92.0\right.$, $P<0.001, n=752$ ). Ramet survival, on the other hand, was not changed due to defoliation (Table 1). Similarly, leaf production was not affected or hardly affected by defoliation (multiple regression, results not shown) and leaf number of defoliated ramets recovered rapidly: after one year $36 \% \pm 11 \%$ (mean $\pm \mathrm{SD}$ ) of the original leaf number was present and after two years $68 \% \pm 19 \%$ was present. Leaf length was reduced only moderately (by $10 \%)$ in defoliated ramets $(t=5.30, P<0.001, n=370)$. Defoliation had intermediate effects on stem growth (Table 1): stem growth of defoliated ramets was reduced by $43 \%$ and $29 \%$ during the first and second year, and was mainly caused by a decrease in internode length.

Within defoliated genets, the undisturbed ramets $(<120 \mathrm{~cm}$ stem length) responded differently to the treatment than the defoliated large ramets. Small ramets in defoliated genets had similar growth rate (Table 1) and similar flowering frequency $\left(\chi^{2}\right.$ tests, $\left.P>0.05\right)$ as those in undisturbed genets.

\section{Consequences of leaf cutting at the population level}

Population structures projected by the models for an undisturbed population closely resembled those observed in the field (similarity index PS $=89 \%$ ). Densities predicted on the basis of $\mathbf{U} \mathbf{1}$ for almost all categories were within the $95 \%$ confidence interval of observed densities, suggesting that transition matrices realistically described actual population dynamics.

Asymptotic population growth rates $(\lambda)$ for undisturbed populations were slightly above unity: 1.034 for $\mathbf{U 1}$ and 1.003 for $\mathbf{U} \mathbf{2}$, but $95 \%$ confidence intervals of $\lambda$ included 1.0 (0.998-1.070 for U1 and 0.981-1.024 for U2), suggesting that populations were neither growing nor decreasing in size in the long run. The lower $\lambda$ in the second year was probably due to exceptionally low rainfall.

Defoliation caused a small decline in $\lambda$ : from 1.034 to 1.012 for the first year (C1, 95\% CI: 0.973-1.051) and from 1.003 to 0.9887 in the second year (C2, 95\% CI: 0.971-1.006). As confidence intervals of $\lambda$ for undisturbed and defoliated populations largely overlapped, differences in $\lambda$ were not significant. Confidence intervals also included the value 1.0, suggesting that treated populations were stable in size. Elasticity distributions slightly changed after defoliation: defoliated populations in both years had higher elasticity values for survival and lower values for growth and reproduction (Fig. 1), but elasticities of harvested and unharvested populations were highly correlated (C1 vs. U1 and $\mathbf{C} 2$ vs. U2, Spearman $r=0.93-0.96, P<0.001)$. 


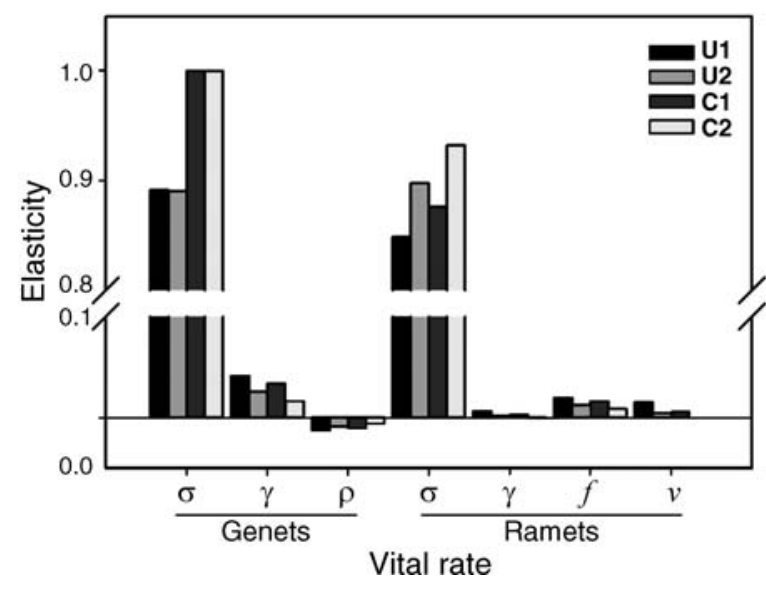

FIG. 1. Elasticity values of vital rates for genets (left) and ramets (right) of Geonoma deversa for an undisturbed population in the first year (U1) and second year (U2), and for a defoliated population in the first year $(\mathbf{C} 1)$ and second year (C2) after defoliation. Vital rate abbreviations are: $\sigma$, survival; $\gamma$, positive growth; $\rho$, negative growth; $f$, sexual reproduction; $v$, vegetative reproduction. The net sum of vital rate elasticities is presented. This value can be negative if an increase in the vital rate causes a decline in $\lambda$.

The results of the LTRE analysis showed similar patterns of contributions for the first and second year after defoliation (Fig. 2). In both years, differences in $\lambda$ between undisturbed and defoliated populations resulted predominantly from the strong decreases in sexual and vegetative reproduction. At the genet level only growth contributed to $\Delta \lambda$, both in a positive and a negative way. Positive LTRE contributions of genet growth were due to the combination of negative sensitivity of growth for some genet categories and reduced genet growth due to defoliation. The small and positive LTRE contribution of ramet growth was caused by a growth reduction in defoliated ramets combined with small negative sensitivities for ramet growth.
Sensitivity of ramet growth could be negative as small ramets of $120-230 \mathrm{~cm}$ produced more vegetative offspring than larger ones: an increase in their growth causes lower vegetative reproduction and thus a reduction in $\lambda$.

The summary statistics on elasticity (Fig. 1) and LTRE contributions (Fig. 2) suggested that those vital rates that contributed most to $\lambda$ (highest elasticity) either remained unchanged or explained only a small part of the difference in $\lambda$ (low LTRE contribution), and vice versa. We indeed found positive correlations between elasticity and defoliation effect (Fig. 3; Kendall rank correlations) for both study years. In fact, two groups of vital rates can be distinguished in Fig. 3, those that were affected by defoliation and have a low elasticity and those that were not changed but have higher elasticities. The median elasticity of the former group was higher than that of the latter for both Year 1 (median elasticity unchanged, 0.029; changed, 0.001; Mann-Whitney $U=$ 234, $P<0.001$ ) and Year 2 (medians, 0.026 and 0.0003 , respectively; Mann-Whitney $U=292, P<0.001$ ).

The relation between LTRE contribution and elasticity for both study years showed that vital rates with the highest elasticity (accounting for 95\% of the total elasticity) did not contribute to $\Delta \lambda$, whereas those with very low elasticity contributed most to $\Delta \lambda$ (Fig. 4; Mann Whitney $U$ tests, $P<0.05$ ). The positive tendency in Fig. 4 is not expected in a null model in which all vital rates have suffered the same proportional decrease due to defoliation. In that case negative correlations are to be expected, as both elasticity and LTRE contribution are calculated using sensitivities (Caswell 2001).

We also assessed how the elasticity-contribution relations (Fig. 4) changed when the most important vital rates (i.e., ramet and genet survival) were changed due to harvest damage. When increasing ramet or genet mortality by $1 \%$, the low-elasticity vital rates still contributed most to $\Delta \lambda$ (Fig. $5 ; 72 \%$ and $79 \%$ for genet
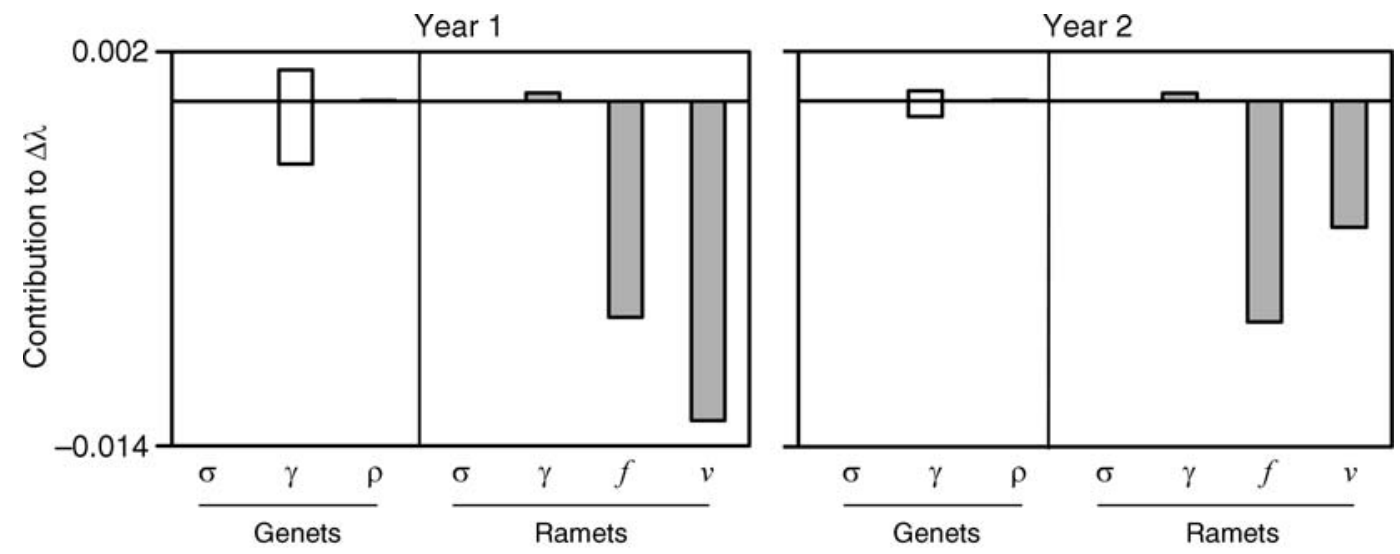

Vital rate

FIG. 2. Results of Life Table Response Experiments (LTRE) for Geonoma deversa. Contributions of vital rates to $\Delta \lambda$ are summed over categories and presented separately for genets (open bars) and ramets (gray bars). Summed contributions closely matched $\Delta \lambda(0 \%-3 \%$ difference). Vital rate abbreviations are as in Fig. 1. 


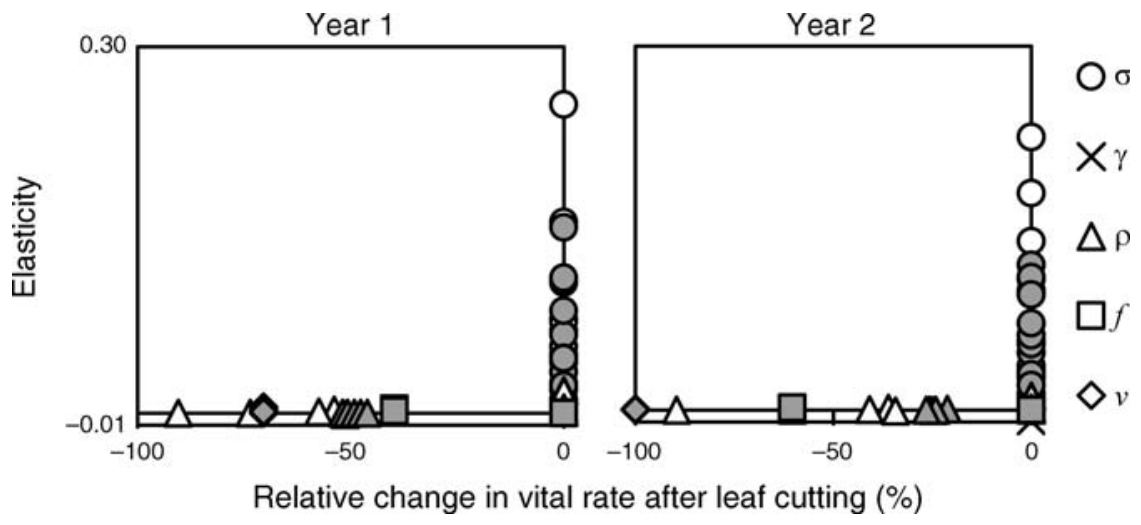

FIG. 3. High-elasticity vital rates remain unaffected after defoliation of Geonoma deversa, and vice versa. Each point represents one vital rate of one size category: gray symbols show ramets, and open symbols show genets. Kendall rank correlations are: Year 1, $\tau=0.47, P<0.001$; Year $2, \tau=0.38, P<0.001$. Vital rate abbreviations are as in Fig. 1 .

and ramet mortality, respectively), although the highelasticity vital rates (that account for $95 \%$ of the total elasticity) did not differ any longer in contribution to $\Delta \lambda$ (Mann Whitney $U, P>0.05$ ). With 5\% extra mortality, changes in survival were responsible for $56 \%$ to $66 \%$ of $\Delta \lambda$ (Fig. 5; ramet mortality, $\Delta \lambda=-0.052$; genet mortality, $\Delta \lambda=-0.066)$.

\section{Defoliation effects and demography in other understory palms}

Defoliation studies on seven understory palm species showed highly similar patterns of defoliation response (Table 2). Survival rate was not affected or hardly affected, whereas the strongest reductions were found for reproduction. Notably, for Geonoma congesta $50 \%$ defoliation had no effect on any vital rate. Elasticity values for seven species of understory palms also showed similar results as obtained for $G$. deversa: adult survival accounted for approximately half of the total vital rate elasticity, whereas growth and reproduction were much less important in determining $\lambda$.
Demographic analyses for two other understory palm species showed that $\lambda$ changed little after harvesting for Astrocaryum mexicanum (from 1.012 to 1.001), while it was substantially decreased for Chamaedorea radicalis (from 1.18 to 1.02 for defoliating once, and from 1.18 to 0.97 for defoliating twice per year). The elasticitycontribution relations for these two species (Fig. 6) were similar to those of $G$. deversa: those vital rates that had the highest elasticity contributed little to $\Delta \lambda$, and vice versa. For both species, fecundity was strongly changed after defoliation, and this vital rate was mainly or entirely responsible for $\Delta \lambda$.

\section{DisCUSSION}

Individual responses to defoliation in Geonoma deversa

Leaf cutting strongly affected sexual and vegetative reproduction, considerably reduced stem growth, but did not affect survival of Geonoma deversa. These results agree with observations in defoliated populations of this species in Peru, which contained smaller genets (probably due to reduced vegetative reproduction) and fewer

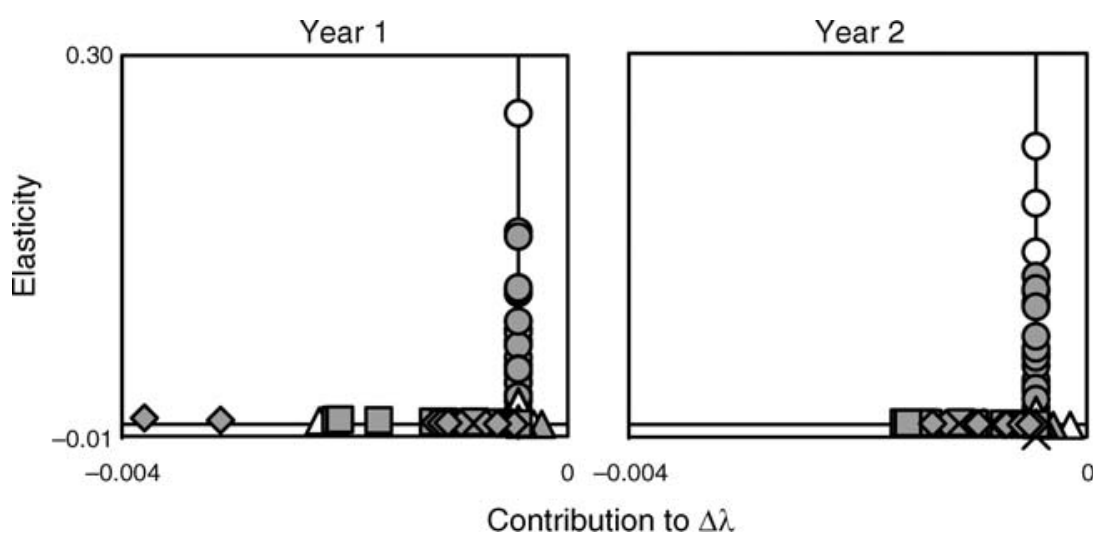

FIG. 4. High-elasticity vital rates do not contribute to the defoliation effect on $\lambda$ for Geonoma deversa, and vice versa. Each point represents one vital rate of one size category: gray symbols for ramets and open symbols for genets. Contributions to $\Delta \lambda$ are based on LTRE analysis. Symbols are as shown in Fig. 3. 

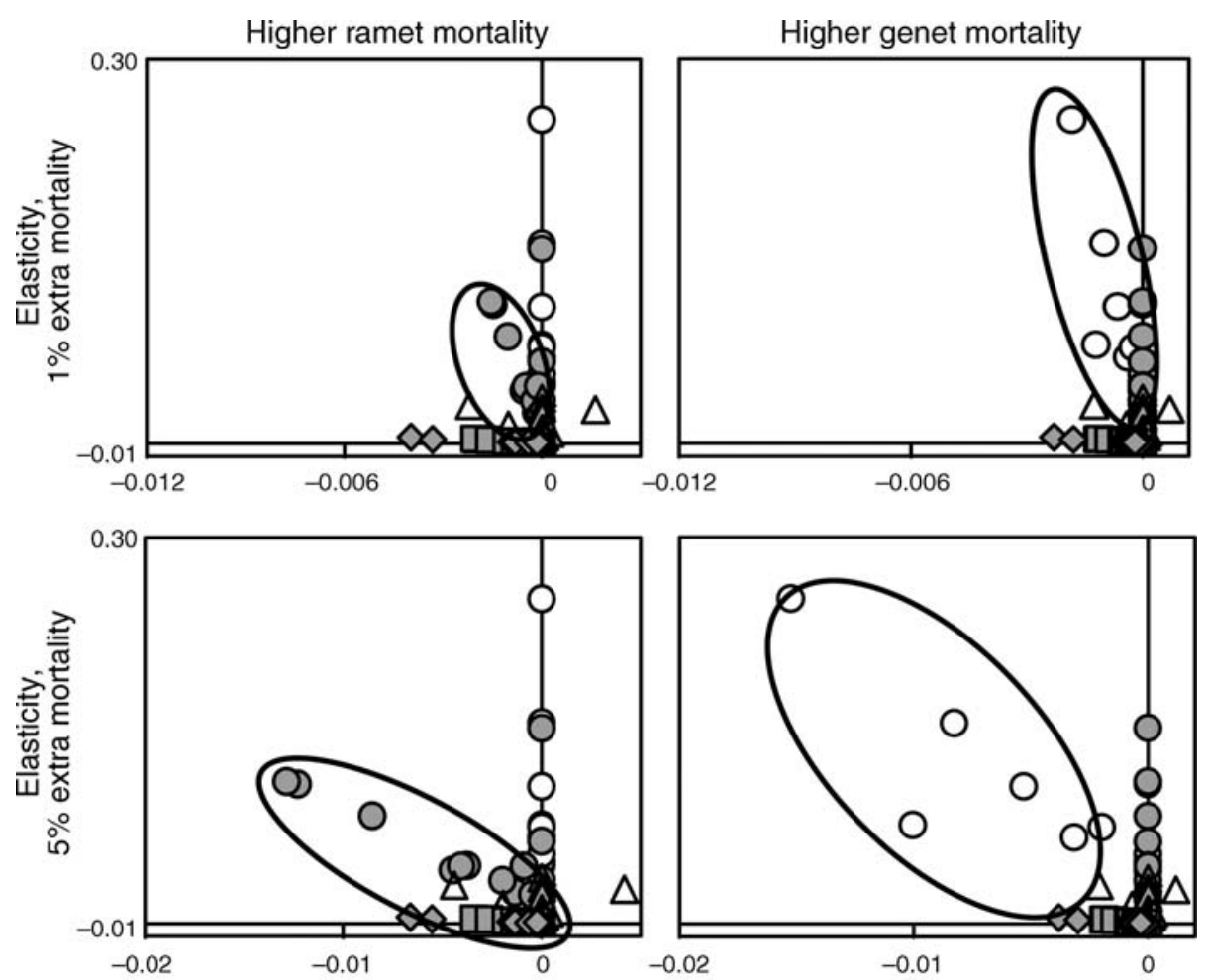

Contribution to $\Delta \lambda$

FIG. 5. Increasing mortality of defoliated ramets (left-hand panels) or genets (right-hand panels) changes elasticity contribution relations in Geonoma deversa. Each point represents one vital rate of one size category: gray symbols for ramets and open symbols for genets. Open ovals include the altered survival values. Symbols are as shown in Fig. 3.

TABLE 2. Defoliation effect and elasticities of 10 forest understory palm species.

\begin{tabular}{|c|c|c|c|c|c|c|c|c|c|c|c|c|}
\hline \multirow[b]{2}{*}{ Species } & \multirow{2}{*}{$\begin{array}{l}\text { Def } \\
(\%) \dagger\end{array}$} & \multicolumn{6}{|c|}{ Defoliation effect (\%) } & \multicolumn{4}{|c|}{ Elasticity } & \multirow[b]{2}{*}{ Source } \\
\hline & & $\sigma$ & $\gamma$ & $\operatorname{Pr}$ & $f$ & $v$ & LP & $\sigma$ & $\gamma$ & $f$ & $v$ & \\
\hline Astrocaryum mexicanum & 67 & 0 & $\cdots$ & -80 & -50 & $\ldots$ & 0 & 55 & 1 & 1 & $\ldots$ & $\begin{array}{l}\text { Piñero et al. (1984); Mendoza } \\
\text { et al. (1987) }\end{array}$ \\
\hline Chamaedorea elegans & 66 & -5 & -43 & -84 & -83 & $\cdots$ & -11 & 61 & 2 & 6 & $\cdots$ & $\begin{array}{l}\text { Anten et al. (2003), and N. P. R. } \\
\text { Anten, D. Ackerly, and M. } \\
\text { Martinez-Ramos, unpublished } \\
\text { data; annual defoliation, 3-yr } \\
\text { mean }\end{array}$ \\
\hline Chamaedorea oblongata & 66 & -2 & -59 & -64 & -86 & $\cdots$ & -6 & 38 & 0.3 & 5 & $\cdots$ & $\begin{array}{l}\text { N. P. R. Anten, D. Ackerly, and } \\
\text { M. Martinez-Ramos, } \\
\text { unpublished data; annual } \\
\text { defoliation, 2-yr mean }\end{array}$ \\
\hline Chamaedorea radicalis & $t$ & -2 & $\ldots$ & -90 & +30 & $\cdots$ & $\cdots$ & 44 & 8 & 6 & $\cdots$ & $\begin{array}{l}\text { Endress et al. (2004a); first yr, } \\
1 \times \text { treatment }\end{array}$ \\
\hline Chamaedorea tepejilote & 100 & 0 & $\cdots$ & 0 & 0 & $\cdots$ & +200 & $\cdots$ & $\cdots$ & $\cdots$ & $\cdots$ & Oyama and Mendoza (1990) \\
\hline Geonoma ce & 50 & 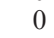 & 0 & 0 & $\cdots$ & $\cdots$ & 0 & $\cdots$ & $\cdots$ & . & $\cdots$ & Chazdon (1991) \\
\hline Geonoma deversa & 100 & 0 & -43 & -40 & $\cdots$ & -70 & -10 & 76 & 0.04 & 2 & 1 & $\begin{array}{l}\text { This study; first yr, only ramet } \\
\text { categories }\end{array}$ \\
\hline Geonoma macrostachy & $\cdots$ & $\cdots$ & $\cdots$ & $\cdots$ & ... & $\cdots$ & $\cdots$ & 64 & 6 & 2 & $\ldots$ & Svenning and Macia (2002) \\
\hline ma orbignyana & $\ldots$ & $\ldots$ & ... & ... & ... & $\ldots$ & $\cdots$ & 3 & 0.9 & 2 & $\ldots$ & Roderiguez-Buritica et al. (2005) \\
\hline Podococcus barteri & $\cdots$ & $\cdots$ & $\cdots$ & $\ldots$ & $\cdots$ & $\cdots$ & $\cdots$ & 55 & 1 & 4 & $\ldots$ & Bullock (1980) \\
\hline
\end{tabular}

Notes: Elasticities of adult categories are shown as a percentage of the total vital rate elasticity for unharvested populations. Vital rate abbreviations: $\sigma$, survival; $\gamma$, positive growth; $\rho$, negative growth; $\operatorname{Pr}$, percentage flowering/fruiting individuals; $f$, seed production; $v$, vegetative reproduction; LP, leaf production. Ellipses $(\cdots)$ indicate that data were not calculated/not applicable.

$\uparrow$ Defoliation (Def) is represented as percentage of harvested leaves.

\$ All harvestable leaves were taken. 

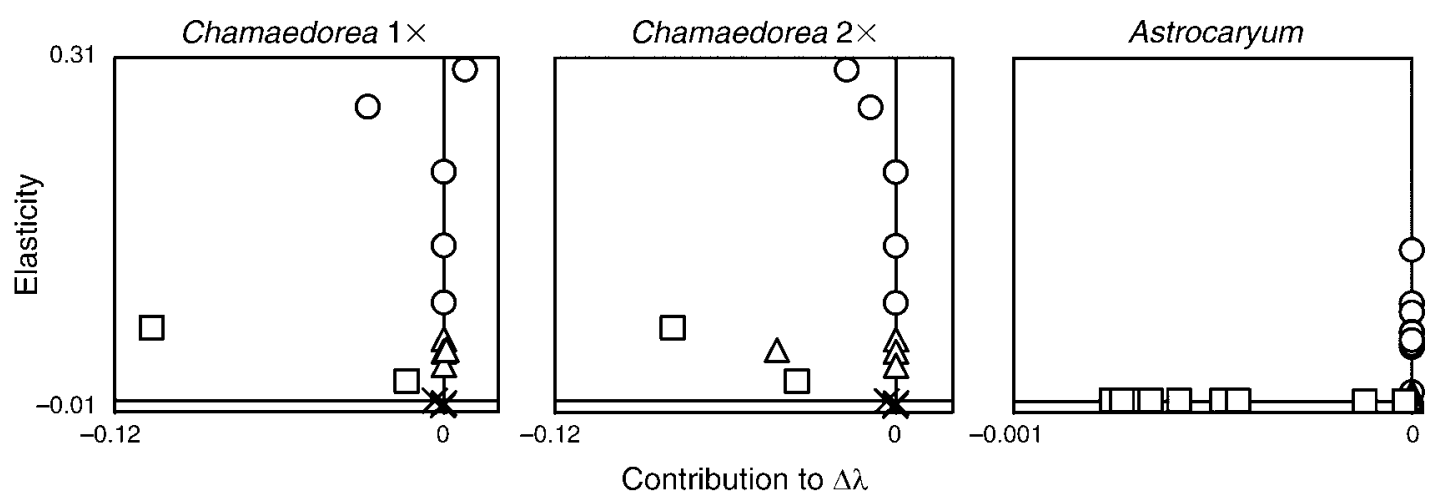

FIG. 6. High-elasticity vital rates contribute little to the defoliation effect on $\lambda$ for Chamaedorea radicalis and Astrocaryum mexicanim. Each point represents one vital rate of one size category. Defoliation treatments: $C$. radicalis, all marketable leaves cut once $(1 \times)$ or twice $(2 \times)$ per year (Endress et al. 2004a, b); A. mexicanum, 67\% of all leaves cut once (Mendoza et al. 1987, Piñero et al. 1984). Symbols are as shown in Fig. 3.

inflorescences than undisturbed populations (Flores and Ashton 2000). They also fit well in the very consistent pattern of defoliation responses for six other understory palms (Table 2), which generally show much stronger reduction in reproduction than in growth, and hardly any change in survival.

Two years after leaf cutting, two-thirds of the harvested leaf area of Geonoma deversa had recuperated. This fast recovery is probably explained by (1) a shift in biomass allocation to leaf production at the cost of allocation to stems and reproduction (cf. Anten et al. 2003), (2) the reallocation of stored reserves to cover leaf construction costs (cf. Stowe et al. 2000, Anten and Ackerly 2001), and (3) increased photosynthesis rates of remaining and new leaves (although probably of limited importance in the dark forest understory; Chazdon 1986, Anten and Ackerly 2001). It remains unclear, though, which of these factors contributed most to leaf recovery.

Defoliated ramets were probably not supported by untreated (small) ramets in the same genet, as treatment effects were confined to the defoliated ramets (Table 1). Among physiologically integrated ramets one would expect such support as a way to mitigate the negative effects of defoliation (Schmid et al. 1988, Price and Hutchings 1992). But this is not the case: the response of Geonoma resembles that of trees and shrubs in which defoliation effects are mostly confined to branches (Sprugel et al. 1991). A possible advantage of this local defoliation response is that it prevents reserve depletion in other ramets and thus does not jeopardize the viability of the genet as a whole (Mendoza and Franco 1998).

\section{Population-level responses to defoliation in Geonoma deversa and other palms}

To evaluate tolerance to leaf cutting it is necessary to quantify the population-level consequences as this integrates the effects over all vital rates and over all individuals (cf. Ehrlen 2003). Nevertheless, most studies on tolerance to natural damage and herbivory considered separate vital rates and their effects for individuals
(Strauss and Agrawal 1999, Stowe et al. 2000). Most defoliation studies for understory plants have also focused on separate vital rates and have not considered the population-level effects (Table 1; but see Endress et al. 2004a).

Our population-level analyses for Geonoma deversa showed that in spite of the strong declines in values of some vital rates, growth rates of defoliated and undisturbed populations were close to 1.0 and did not differ significantly. In the only other study on population consequences of understory palm defoliation (for Chamaedorea radicalis; Endress et al. 2004a), leaf cutting did reduce population growth, but the $\lambda$ in the undisturbed population in that study was very high (1.17-1.18), probably due in part to zero mortality in some categories. Our analysis for Geonoma deversa showed that the defoliation response did not follow the null model in which all vital rates are equally affected. Instead, vital rates that contributed most to population growth were least affected by defoliation, and vice versa (Fig. 3). Similar relations are also expected for other understory palm species as defoliation effects and elasticity distributions are highly similar (Table 2).

Relations between elasticity and vital rate variation (e.g., Pfister 1998, Zuidema and Franco 2001) have recently been criticized as they may be partially based on spurious correlations due to scaling differences among vital rates (Morris and Doak 2004). Our correlations differ from those referred to by Morris and Doak (2004) as we considered changes in vital rates in an experimental setting (not their temporal variability), and as the potential decrease in vital rates was not limited by the value for an undisturbed situation. For instance, the potential for survival reduction in our study was large (values close to $100 \%$ ), but this vital rate was not changed at all. On the other hand, the potential change in vegetative reproduction was rather low, but this vital rate changed strongly. Thus we are confident that the spurious correlations detected by Morris and Doak (2004) have not affected the correlations in Fig. 4. 


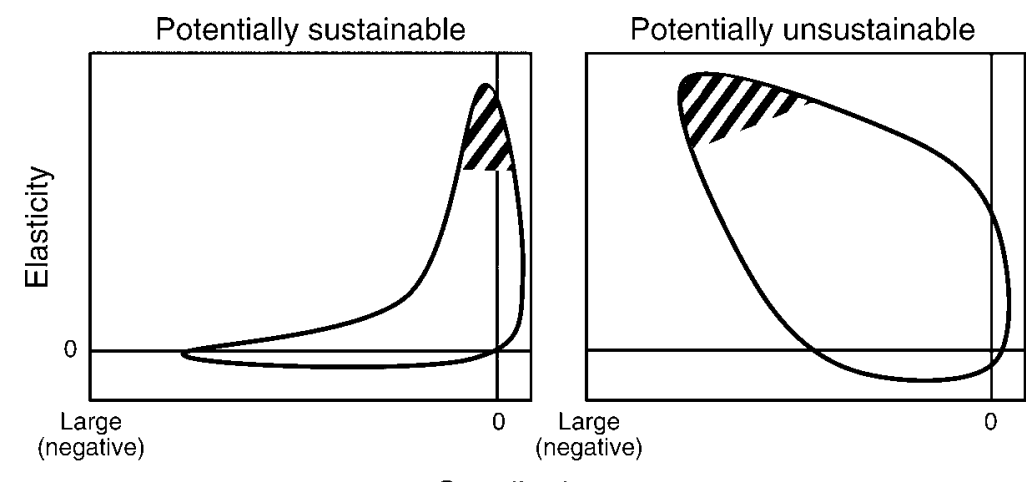

Contribution to $\Delta \lambda$

FIG. 7. Schematic representation of the elasticity contribution relationship for potentially sustainable and unsustainable harvesting. In sustainable harvesting, high-elasticity vital rates (hatched area) contribute little or nothing to $\Delta \lambda$ (compare with Figs. 4 and 6). In unsustainable harvesting, high-elasticity vital rates have large contributions to $\Delta \lambda$ (compare with Fig. 5 , lower panels).

The relations in Fig. 4 are consistent with an adaptive response to defoliation, as vital rates that are most important for population maintenance were least changed. Such adaptive response may be found for our study species if it has experienced a selection pressure with a similar effect as leaf harvesting. It is likely that the frequent damage to leaves caused by falling debris (Clark and Clark 1989, 1991) has acted as a selective force for Geonoma deversa and other forest understory palms. As these palms complete their entire (and often long) life cycle under conditions of frequent small-scale disturbances, responses to leaf loss (or damage) that minimize the negative effects for population growth will be favored as they increase fitness (cf. Pfister 1998).

\section{Implications for palm leaf harvesting}

For our study species and two other understory palm species, we showed that there are good prospects for sustainable harvesting, as high-elasticity vital rates contributed little or nothing to shifts in population growth rate (Figs. 4 and 6). In one of the analyzed species (Chamaedorea radicalis) the shift in population growth rate was large, but also here mainly resulting from changes in low-elasticity vital rates. The distribution of defoliation effects and elasticity values over vital rates for several other understory palm species (Table 2) suggests that such relations may be generally expected for understory palms. The distribution of elasticity values is consistent with the general finding that survival is critical for population maintenance in long-lived plant species such as shrubs and trees (Franco and Silvertown 2004).

We also showed that the elasticity-contribution relations strongly changed when harvest-induced mortality was added: if defoliation leads to $5 \%$ extra mortality, high-elasticity vital rates are mainly responsible for the (larger) decrease in population growth (Fig. 5). This analysis clearly points out that harvesting methods that involve stem cutting strongly reduce populations as they affect a crucial vital rate (cf. Franco and Silvertown 2004) and cannot be sustainable (cf. Flores and Ashton 2000, Svenning and Macia 2002).

Our results have important management implications for leaf harvesting in understory palms. The consistent defoliation responses across species strongly suggest that there is a good scope for sustainable leaf harvest and thus for the formulation of generic extraction guidelines and certification criteria for leaf extraction from forest understory palms. It should be noted though that our results are mainly based on the effects of single defoliation events. If defoliation is repeated, which is often happening, care should be taken to allow sufficient recuperation time between successive harvests (Milton and Moll 1988, Anten et al. 2003, Endress et al. $2004 a, b)$. In those cases, we suggest that the amount of harvested or harvestable leaves be monitored over time, which allows adjustment of harvest intensity or frequency. Monitoring is also useful to observe changes in harvest pressure over time.

\section{Combining prospective and retrospective analyses to evaluate sustainability}

We presented a new approach to evaluating the potential of sustainable harvest of plant parts that combines prospective analysis (elasticities of vital rates) and retrospective analysis (contribution of vital rates to $\Delta \lambda$ from LTRE analysis; Horvitz et al. 1997). Retrospective analysis has hardly been used in harvest impact studies (but see Martínez-Ballesté et al. 2005), although it is a powerful tool for such analyses. We plotted elasticities against LTRE contributions of vital rates, and derived indications for sustainability from these relations (Fig. 7). If high-elasticity vital rates make a small contribution to the harvest-induced difference in population growth there is a very good prospect for sustainable harvest (Fig. 7, left panel). By contrast, if the largest contributions to change in population growth are made by essential (high-elasticity) vital rates, there is little scope for sustainable harvest (Fig. 7, right panel). Clearly, the scope for sustainable exploitation also 
depends on the magnitude of the change in $\lambda$ resulting from harvest: in harvested populations $\lambda$ should not decrease to values much lower than 1.0. Such strong decreases, though, will probably be reflected in the elasticity-LTRE contribution plots, as they are mostly due to changes in high-elasticity vital rates. Nevertheless, the approach presented here primarily evaluates the potential for sustainable use, and does not provide exact estimates of future population growth, future harvestable stock, or maximum sustainable yield.

The advantage of our approach over the commonly used comparison of growth rates of undisturbed and exploited populations (e.g., Peters 1990a, $b$, Ratsirarson et al. 1996, Bernal 1998) is that it is less sensitive to random fluctuations in $\lambda$. There is accumulating evidence that natural variation, sampling errors, and measurement errors strongly influence $\lambda$ (e.g., Wisdom et al. 2000, Zuidema and Franco 2001, Ticktin et al. 2002), resulting in wide confidence intervals for $\lambda$ (Alvarez-Buylla and Slatkin 1994, Caswell 2001). As a consequence, $\lambda=1.0$ is often not a reliable criterion for sustainable exploitation and may lead to erroneous conclusions, although conceptually it is sound. Our approach applies elasticities that are rather robust to changes in $\lambda$ (de Kroon et al. 2000), and LTRE contributions that are based on relative changes in vital rates and sensitivities (not on $\lambda$ ). Only in the case that $\lambda$ of the undisturbed population departs strongly from 1.0 (e.g., $<0.9$ or $>1.1$ ), care should be taken with the interpretation of elasticity values, but this is very unusual for plants yielding nontimber forest products that are often perennial herbs, shrubs, or trees (Franco and Silvertown 2004).

A second advantage of our approach is that it is less sensitive to chance fluctuations in treatment effects, as we tested for defoliation effects on vital rates prior to model construction. Only when defoliation significantly affected vital rates were different values used for models of undisturbed and defoliated populations. This procedure avoids random events (e.g., sporadic mortality) from strongly influencing $\lambda, \Delta \lambda$, and LTRE contributions.

The approach presented here can be applied to other species yielding nontimber forest products or, as we have done, to groups of ecologically resembling species that yield similar products (e.g., rattans from clonal climbing palms, palm hearts from clonal palms, resins and gums from trees). Group-wise evaluations may facilitate the establishment of generic harvest guidelines and certification criteria for product groups. Such guidelines are clearly needed, as it is impossible to derive specific guidelines for all species yielding nontimber forest products.

\section{ACKNOWLEDGMENTS}

We are grateful to Luis Apaza, Rene Aramayo, Nazareno Martinez, and several inhabitants of El Turi for support with the field work, and to the community of El Turi for hospitality. We thank Niels Anten and Miguel Martinez-Ramos for the use of unpublished data. Niels Anten, Rene Boot, Graham Floater,
Jan van Groenendael, and two anonymous reviewers are acknowledged for comments on draft versions of this paper. This study was partly funded by grants BO 009701 and BO 009703 of the Netherlands Ministry of Foreign Affairs.

\section{Literature Cited}

Alvarez-Buylla, E. R., and M. Slatkin. 1994. Finding confidence limits on population growth rates: three real examples revised. Ecology 75:255-260.

Anten, N. P. R., and D. Ackerly. 2001. Canopy-level photosynthetic compensation after defoliation in a tropical understorey palm. Functional Ecology 15:252-262.

Anten, N. P. R., M. Martinez-Ramos, and D. Ackerly. 2003. Compensatory growth in a tropical understory palm subjected to repeated defoliation. Ecology 84:2905-2918.

Bernal, R. 1998. Demography of the vegetable ivory palm Phytelephas seemannii in Colombia, and the impact of seed harvesting. Journal of Applied Ecology 35:64-74.

Boot, R. G. A., and R. E. Gullison. 1995. Approaches to developing sustainable extraction systems for tropical forest products. Ecological Applications 5:896-903.

Bullock, S. H. 1980. Demography of an undergrowth palm in Littoral Cameroon. Biotropica 12:247-55.

Caswell, H. 2001. Matrix population models: construction, analysis, and interpretation. Second edition. Sinauer Associates, Sunderland, Massachusetts, USA.

Chazdon, R. L. 1986. Light variation and carbon gain in rain forest understorey palms. Journal of Ecology 74:995-1012.

Chazdon, R. L. 1991. Effects of leaf and ramet removal on growth and reproduction of Geonoma congesta, a clonal understorey palm. Journal of Ecology 79:1137-1146.

Clark, D. B., and D. A. Clark. 1989. The role of physical damage in the seedling mortality regime of a neotropical rain forest. Oikos 55:225-230.

Clark, D. B., and D. A. Clark. 1991. The impact of physical damage on canopy tree regeneration in tropical rain-forest. Journal of Ecology 79:114-157.

Cooch, E., R. F. Rockwell, and S. Brault. 2001. Retrospective analysis of demographic responses to environmental change: a Lesser Snow Goose example. Ecological Monographs 71: 377-400.

de Kroon, H., J. van Groenendael, and J. Ehrlen. 2000. Elasticities: a review of methods and model limitations. Ecology 81:607-618.

Ehrlen, J. 2003. Fitness components versus total demographic effects: evaluating herbivore impacts on a perennial herb. American Naturalist 162:796-810.

Endress, B. A., D. L. Gorchov, and R. B. Noble. 2004a. Nontimber forest product extraction: effects of harvest and browsing on an understory palm. Ecological Applications 14: 1139-1153.

Endress, B. A., D. L. Gorchov, M. B. Peterson, and E. P. Serrano. 2004b. Harvest of the palm Chamaedorea radicalis, its effects on leaf production, and implications for sustainable management. Conservation Biology 18:822-830.

FAO. 2005. State of the world's forests. 2005. Food and Agriculture Organization of the United Nations (FAO), Rome, Italy.

Flores, M., and P. M. S. Ashton. 2000. Harvesting impact and economic value of Geonoma deversa, Arecaceae, an understorey palm used for roof thatching in the Peruvian Amazon. Economic Botany 54:267-277.

Franco, M., and J. Silvertown. 2004. Comparative demography of plants based upon elasticities of vital rates. Ecology 85: 531-538.

Guillen, A., S. A. Laird, P. Shanley, and A. R. Pierce. 2002. Tapping the green market: certification and management of non-timber forest products. Earthscan, London, UK.

Hall, P., and K. S. Bawa. 1993. Methods to assess the impact of extraction of non-timber tropical forest products on plant populations. Economic Botany 47:234-247. 
Horvitz, C. C., and D. W. Schemske. 1995. Spatiotemporal variation in demographic transitions of a tropical understory herb: projection matrix analysis. Ecological Monographs 65: 155-192.

Horvitz, C. C., D. W. Schemske, and H. Caswell. 1997. The relative "importance" of life-history stages to population growth: prospective and retrospective analyses. Pages $247-$ 271 in S. Tuljapurkar and H. Caswell, editors. Structured population models in marine, terrestrial, and freshwater systems. Chapman and Hall, New York, New York, USA.

Martínez-Ballesté, A., C. Martorell, M. Martínez-Ramos, and J. Caballero. 2005. Applying retrospective demographic models to assess sustainable use: the Maya management of xa'an palms. Ecology and Society 10:17. 〈http://www. ecologyandsociety.org/vol10/iss2/art17/ $\rangle$

Mendoza, A., and M. Franco. 1998. Sexual reproduction and clonal growth in Reinhardtia gracilis (Palmae), an understorey tropical palm. American Journal of Botany 85:521527.

Mendoza, A., D. Piñero, and J. Sarukhan. 1987. Effects of experimental defoliation on growth, reproduction and survival of Astrocaryum mexicanum. Journal of Ecology 75: $545-554$.

Milton, S. J., and E. J. Moll. 1988. Effects of harvesting on frond production of Rumohra adiantiformis (Pteridophyta: Aspidiaceae) in South Africa. Journal of Applied Ecology 25: $725-743$.

Moraes, M., J. Sarmiento, and E. Oviedo. 1995. Richness and uses in a diverse palm site in Bolivia. Biodiversity and Conservation 4:719-727.

Morris, W. F., and D. F. Doak. 2004. Buffering of life histories against environmental stochasticity: accounting for a spurious correlation between the variabilities of vital rates and their contributions to fitness. American Naturalist 163:579590 .

Oyama, K., and A. Mendoza. 1990. Effects of defoliation on growth, reproduction, and survival of a neotropical dioecious palm, Chamaedora tepejilote. Biotropica 22:119-123.

Peres, C. A., et al. 2003. Demographic threats to the sustainability of Brazil nut exploitation. Science 302:21122114.

Peters, C. M. 1990a. Plant demography and the management of tropical forest resources: a case study of Brosimum alicastrum in Mexico. Pages 265-272 in A. Gomez-Pompa, editor. Rain forest regeneration and management. Man and Biosphere series, UNESCO, Paris, France.

Peters, C. M. 1990b. Population ecology and management of forest fruit trees in Peruvian Amazonia. Pages 86-89 in A. B. Anderson, editor. Alternatives to deforestation: steps toward sustainable use of the Amazon rain forest. Columbia University Press, New York, New York, USA.

Pfister, C. A. 1998. Patterns of variance in stage-structured populations: Evolutionary predictions and ecological impli- cations. Proceedings of the National Academy of Sciences (USA) 95:213-218.

Piñero, D., M. Martinez-Ramos, and J. Sarukhan. 1984. A population model of Astrocaryum mexicanum and a sensitivity analysis of its finite rate of increase. Journal of Ecology 72:977-991.

Price, E. A. C., and M. J. Hutchings. 1992. Studies of growth in the clonal herb Glechoma hederacea II. The effects of selective defoliation. Journal of Ecology 80:39-47.

Ratsirarson, J., J. A. Silander, and A. F. Richard. 1996. Conservation and management of a threatened Madagascar palm species, Neodypsis decaryi, Jumelle. Conservation Biology 10:40-52.

Roderiguez-Buritica, S., M. A. Orhuela, and G. Galeano. 2005. Demography and life history of Geonoma orbignyana: an understory palm used as foliage in Colombia. Forest Ecology and Management 211:329-340.

Schmid, B., G. M. Puttick, K. H. Burgess, and F. A. Bazzaz. 1988. Clonal integration and effects of simulated herbivory in old-field perennials. Oecologia 75:465-471.

Sprugel, D. G., T. M. Hinckley, and W. Schaap. 1991. The theory and practice of branch autonomy. Annual Review of Ecology and Systematics 22:309-334.

Stowe, K. A., R. J. Marquis, C. G. Hochwender, and E. L. Simms. 2000. The evolutionary ecology of tolerance to consumer damage. Annual Review of Ecology and Systematics 31:565-595.

Strauss, S. Y., and A. A. Agrawal. 1999. The ecology and evolution of plant tolerance to herbivory. Trends in Ecology and Evolution 14:179-185.

Svenning, J.-C., and M. J. Macía. 2002. Harvesting of Geonoma congesta Mart. leaves for thatch: an exploration of sustainability. Forest Ecology and Management 167:251-262.

Ticktin, T. 2004. The ecological implications of harvesting nontimber forest products. Journal of Applied Ecology 41:11-21.

Ticktin, T., P. Nantel, F. Ramirez, and T. Johns. 2002. Effects of variation on harvest limits for nontimber forest species in Mexico. Conservation Biology 16:691-705.

Wessels Boer, J. G. 1968. The Geonomoid palms. Verhandelingen der Koninklijke Nederlandse Akademie van Wetenschappen (Afd. Natuurkunde, Tweede reeks) 58:1-202.

Wisdom, M. J., L. S. Mills, and D. F. Doak. 2000. Life stage simulation analysis: estimating vital-rate effects on population growth for conservation. Ecology 81:628-641.

Zuidema, P. A. 2000. Demography of exploited tree species in the Bolivian Amazon. Dissertation. Utrecht University, The Netherlands. PROMAB Scientific Series 2.

Zuidema, P. A., and M. Franco. 2001. Integrating vital rate variability into perturbation analysis: an evaluation for matrix population models of six plant species. Journal of Ecology 89:995-1005.

\section{APPENDIX}

Parameterization of transition matrices (Ecological Archives A017-006-A1). 